\title{
Insulin pump therapy-a different solution for treating diabetes type I
}

Sladjana Pejakovic ${ }^{1}$, Jovana Prodanovic ${ }^{1}$, Dragan Tesic ${ }^{1}$, Edita Stokic ${ }^{1}$, Andrijana Milankov ${ }^{1}$, Milena Mitrovic ${ }^{1}$, Branka Kovacev-Zavisic $^{1}$

Clinic of endocrinology, diabetes and metabolism diseases, Clinical Center of Vojvodina, Faculty of medicine, University of Novi Sad, Serbia.

\section{Objectives:}

Continuous Subcutaneous Insulin Infusion via insulin pump is the most efficient way of imitating physiological insulin secretion, and it also provides better management of diabetes, lower rate of hypoglicemic episodes, better quality of life and prevention of long-term complications of diabetes mellitus. Aim of the research was to determine effects of subcutaneous insulin infusion therapy on parameters of glycoregulation during the two years trial.
Methods:

Research was conducted at Clinic for endocrinology, diabetes and diseases of metabolism, Clinical center of Vojvodina, where 80 patients were treated this way during period of time from 2007. to 2015. There are complete results assembled for 60 patients with type I diabetes, from that 45 women, average age $31.67 \pm 8.03$ and 15 men average age $26.06 \pm 8.25$ years. In all subjects following parameters were monitored: sex, age, medical indications for this kind of therapy, complications of therapy, HbA1c (glycated haemoglobin) in the moment of insulin pump application, after 6 months, one year and two years of therapy.

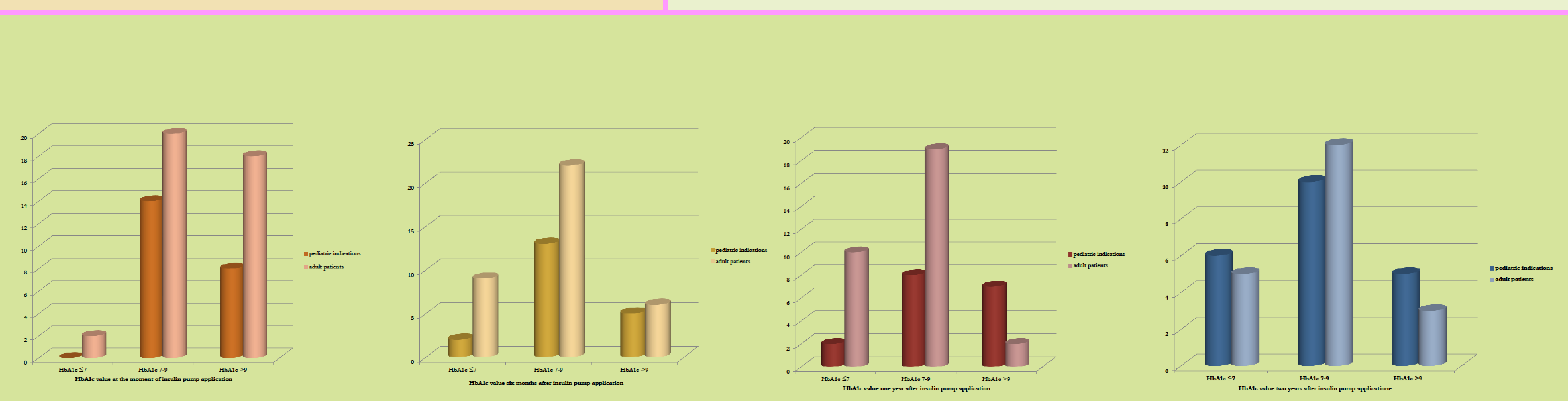

Results:

The main indication for insulin pump application was diabetic nephropathy (in $70 \%$ of cases) while pregnancy was in $30 \%$ of cases indication for this kind of treatment. After starting with insulin pump therapy, better glycoregulation was notified, through statistically significant decrease in $\mathrm{HbA} 1 \mathrm{c}$ rates after 6,12 and 24 months. The biggest decrease in $\mathrm{HbA} 1 \mathrm{c}$ rate was in those patients who had poorly regulated diabetes with $\mathrm{HbA} 1 \mathrm{c}>10 \%$ in the moment of insulin pump application (usually former pediatric patients).

\section{Conclusions:}

There is significant decrease in $\mathrm{HbA} 1 \mathrm{c}$ rate after application of the insulin pump, and it is also confirmed that the biggest reduction in $\mathrm{HbA} 1 \mathrm{c}$ rate $(2-3 \%)$ was in those patients who had the worst glycoregulation $(\mathrm{HbA} 1 \mathrm{c}>10 \%)$. Reduction of $\mathrm{HbA} 1 \mathrm{c}$ did not result in higher rates of hypoglicemic episodes, while ketoacidosis was developed in 2 patients. 